\title{
Serological and Immunological Properties of Isolated Enterobacterial Common Antigen
}

\author{
Daniela MÄNNEL and Hubert MAYER \\ Max-Planck-Institut für Immunbiologie, Freiburg i. Br.
}

(Received November 14, 1977)

Enterobacteriaceae common antigen (sometimes abbreviated to ECA) isolated from Salmonella montevideo by a combination of phenol/water and phenol/chloroform/petroleum ether extraction procedures and further purified by ion-exchange chromatography was investigated relative to its serological and immunological properties.

The isolated material was highly active in coating erythrocytes for agglutination with antisera specific for enterobacterial common antigen and in inhibition of hemagglutinating systems established for this antigen. With some high-titered antisera to enterobacterial common antigen the material precipitated in a characteristic bird-wing pattern after immunoelectrophoresis at $\mathrm{pH}$ 8.6. Alkalitreated material gave a single precipitin line indicating that it was more uniform than the untreated enterobacterial common antigen, which was probably partly cross-linked. An additional weak precipitin line, located close to the antiserum trough, was occasionally observed. Specific serum absorptions with genetically defined ECA-negative $r f e^{-}$or $r f f^{-}$mutants did not influence the precipitation pattern at all, whereas simiiar absorptions with living or heat-killed ECA-positive strains removed all precipitating antibodies.

Esterification of the carboxylic groups of the D-mannosaminuronic acid residues in enterobacterial common antigen leads to a reversible loss of its precipitating capacity, proving that this aminuronic acid is an essential part of the serological determinant of this antigen.

Attempts to immunize rabbits with the isolated, soluble enterobacterial common antigen were unsuccessful. High titers were, however, elicited in rabbits and NMRI mice when the immunization was carried out with the antigen attached to acetic-acid-hydrolyzed $S$. minnesota R595 bacteria according to the technique of Galanos. The specificity of the immune response was ascertained by absorbing the sera with closely related pairs of ECA-positive and ECA-negative enterobacterial strains.

The data show that the material isolated as enterobacterial common antigen from $S$. montevideo has retained the serological and immunological characteristics of the antigen which was first described and defined by Kunin.

An antigen common to almost all members of the Enterobacteriaceae family was described by Kunin et al. [1] in 1962 and designated as enterobacterial common antigen [2]. This antigen, sometimes abbreviated as ECA [3], readily coats erythrocytes for agglutination by antibodies to enterobacterial common antigen and is thus easily demonstrable in supernatants of heated bacterial cultures $[1,4,5]$. Only a limited number of defined $\mathrm{R}$ mutants of Escherichia coli and Shigella, notably the encapsulated R strain E. coli $014: \mathrm{K} 7[1,6]$ induce antibodies to enterobacterial common antigen in the rabbit by intravenous

Abbreviations. ECA, enterobacterial common antigen; GlcN, D-glucosamine; ManNUA, D-mannosaminuronic acid. injection of bacterial suspensions. Other enterobacterial strains contain the antigen in a non-immunogenic soluble form. Immunization with these strains does not usually lead to antibody formation against enterobacterial common antigen in the rabbit, especially when heat-killed bacteria are used for immunization [7]. Nevertheless, isolated enterobacterial common antigen from these non-immunogenic strains can be made immunogenic by separating it from O-antigen which acts as an immunosuppressant [8], by increasing its state of aggregation [9], or by immunization in the presence of Freund's adjuvant [10].

In a recent study (see preceding paper) we have shown that free enterobacterial common antigen 
from a non-immunogenic Salmonella strain (S. montevideo SH94) could be isolated by a combination of phenol/water and phenol/chloroform/petroleum ether extraction procedures. It was further purified by passing it over a DEAE-cellulose column and elution with ammonium acetate/methanol buffer of increasing concentration. Chemical analysis of the isolated material revealed that this antigen is an amino sugar heteropolymer built predominantly by alternating units of $N$-acetyl-D-glucosamine and $N$-acetyl-D-mannosaminuronic acid, which are partly esterified by palmitic acid. Both amino sugars are 1,4-linked and form a chain of molecular weight about 2700 . It is possible that a hitherto undetected lipid constituent might be present as an additional constituent. This constituent could account for the observed low solubility in water and for the unaccountable $30 \%$ (on a weight basis) of the material.

The data presented in this paper show that the isolated material has retained all the serological and immunological properties of the common enterobacterial antigen as described and defined by Kunin [2]. It will further be shown that the rare sugar D-mannosaminuronic acid can serve as a marker substance for this antigen and for distinguishing it from other common antigens which probably are present $[11,3]$.

\section{MATERIALS AND METHODS}

\section{Bacteria and Bacterial Antigens}

The enterobacterial strains used for this study are listed in Table 1. Also shown is their known genetic defects and their origin. Bacteria were cultivated as described previously [19]. A detailed description of the isolation and purification of enterobacterial common antigen is given in the preceding paper.

Isolated $\mathrm{K} 56$ antigen from E. coli 08 : $\mathrm{K} 56$ was kindly supplied by H. C. Flemming (Max-Planck-Institut für Immunbiologie, Freiburg, F.R.G.), M. lysodeikticus cell wall polysaccharide by S. Hase (Department of Chemistry, Osaka University, Toyonaka, Japan), and purified lipoprotein of E. coli B by V. Braun (Mikrobiologie II, University of Tübingen, F.R.G.).

\section{Antisera}

Unless otherwise stated, rabbit antisera were prepared by intravenous immunization of New Zealand White rabbits of both sexes at 4-day intervals with increasing amounts $(0.25,0.5$, and $1.0 \mathrm{ml})$ of bacterial suspensions $\left(10^{10}\right.$ cells $\left./ \mathrm{ml}\right)$. The bacteria were either living or heat-killed $\left(1 \mathrm{~h}\right.$ at $\left.100^{\circ} \mathrm{C}\right)$ and were thoroughly washed with saline. Rabbits were bled 6 days after the last injection [12] and the sera decomplemented by heating $\left(30 \mathrm{~min}\right.$ at $\left.56^{\circ} \mathrm{C}\right)$.
Table 1. The bacterial strains used in this study

Gene symbols: $r f a, r f a L, r f b$, and $r f f$, genes participating in the biosynthesis of lipopolysaccharide and/or enterobacterial common antigen. his, histidine; ${ }^{4}$, deletion

\begin{tabular}{|c|c|c|c|c|}
\hline Strain & Species & Serotype & $\begin{array}{l}\text { Relevant } \\
\text { genotype }\end{array}$ & Reference \\
\hline F 2387 & E. coli & $014: \mathrm{K} 7: \mathrm{H}^{-}$ & & {$[6,12]$} \\
\hline F 1327 & E. coli & $014: \mathrm{K} 7: \mathrm{H}^{-}$ & $r f e^{-}$ & $\begin{array}{l}\text { G. Schmidt, } \\
\text { unpubl. }\end{array}$ \\
\hline F 470 & E. coli & $08^{-}: \mathrm{K} 27^{-}: \mathrm{H}^{-}$ & $r f b^{-}$ & {$[12]$} \\
\hline F 614 & E. coli & $08^{-}: \mathrm{K} 27^{-}: \mathrm{H}^{-}$ & $r f a L^{-}$ & [12] \\
\hline F 1283 & E. coli & $08^{-}: \mathrm{K} 27^{-}: \mathrm{H}^{-}$ & $r f e^{-}$ & {$[13]$} \\
\hline F 1373 & E. coli & $08^{-}: \mathrm{K} 27^{-}: \mathrm{H}^{-}$ & $r f f$ & $\begin{array}{l}\text { G. Schmidt, } \\
\text { unpubl. }\end{array}$ \\
\hline D $21 \mathrm{e} 8$ & E. coli & $\mathrm{K} 12$ & & [14] \\
\hline R 595 & S. minnesota & & $r f a^{-}, r f e^{-}$ & [15] \\
\hline F 1119 & S. minnesota & & $r f e^{-}$ & {$[15]$} \\
\hline SH 3786 & S. minnesota & & $r f f^{-}$ & [3] \\
\hline his 386 & S. typhimurium & & $r f b^{4}, r f f^{-}$ & {$[16,17]$} \\
\hline his 642 & S. typhimurium & & $r f b^{\Delta}$ & {$[16,17]$} \\
\hline SH 94 & S. montevideo & wild type & & \\
\hline F 3140 & $\begin{array}{l}\text { Shigella boydii } \\
\text { Proteus rettgeri }\end{array}$ & $\begin{array}{l}\text { type } 3^{-} \\
\text {wild type }\end{array}$ & $r f b^{-}$ & $\begin{array}{l}{[7]} \\
{[18]}\end{array}$ \\
\hline
\end{tabular}

Mice (NMRI, female, 6-8-weeks old) were immunized on days $1,7,14$, and 27 either intravenously, intraperitoneally, or subcutaneously, with a total volume of $0.2 \mathrm{ml}$ of a heat-killed bacterial suspension $\left(10^{8}-10^{6}\right.$ cells $\left./ 0.2 \mathrm{ml}\right)$. Blood samples were taken at 7 -day intervals from the tail vein.

For immunization with coated acetic-acid-treated $S$. minnesota R595 bacteria, the method of Galanos et al. [20] was adopted. Dried bacteria were washed twice with $1 \%$ acetic acid, then suspended in $1 \%$ acetic acid ( $1 \mathrm{~g}$ bacteria in $50 \mathrm{ml}$ diluted acid) and heated for $1 \mathrm{~h}$ at $100{ }^{\circ} \mathrm{C}$. After cooling, they were washed with distilled water and freeze-dried. Amounts of about $1 \mathrm{mg}$ of the bacterial lyophilysate $\left(\approx 10^{9}\right.$ cells $)$ were coated with different amounts $(1-500 \mu \mathrm{g})$ of isolated enterobacterial common antigen by incubation for $1 \mathrm{~h}$ at $37^{\circ} \mathrm{C}$. Excess antigen was removed by washing the bacterial cells three times with saline. Appropriate dilutions $\left(10^{8}-10^{6}\right.$ cells $\left./ 0.2 \mathrm{ml}\right)$ were prepared in saline and used for immunization of rabbits and mice.

Rabbit antisera against lipoprotein were prepared as described previously [21].

\section{Serum Absorptions}

For serum absorption the overnight growth of 6-8 small Petri dishes was used to absorb amounts of $0.5 \mathrm{ml}$ of $1: 10$ diluted antisera. Absorptions were done with heated $\left(1 \mathrm{~h}\right.$ at $\left.100{ }^{\circ} \mathrm{C}\right)$ or living bacterial suspensions for $2 \mathrm{~h}$ at $37^{\circ} \mathrm{C}$. Additional absorptions of undiluted antisera were performed with coated glutaraldehyde-preserved human red blood cells [22]. 
Briefly, $20 \mu \mathrm{l}$ packed human red blood cells were used for the absorption of $100 \mu \mathrm{l}$ antiserum; they were either coated with supernatant material of heated bacterial cultures or remained uncoated.

\section{Reduction and Esterification of the ManNUA in Enterobacterial Common Antigen}

The reduction of the carboxylic groups of the mannosaminuronic acid residues in the polymer was achieved by the method of Taylor and Conrad [23] as described in the preceding paper. For esterification the material was desalted by passage over a Dowex 50 $\left(\mathrm{H}^{+}\right.$form) column and dissolved in methanol. A solution of diazomethane in ether was then added and the mixture was kept at $25^{\circ} \mathrm{C}$ for $30 \mathrm{~min}$. Methanol and ether were removed under reduced pressure and the esterified sample was freeze-dried.

\section{Serological Methods}

Passive hemagglutination and the hemagglutination inhibition test were performed with fresh human erythrocytes of blood group A as described in detail in the preceding paper. Sensitation of erythrocytes was either achieved with untreated enterobacterial common antigen, with alkali-treated $(0.25 \mathrm{M} \mathrm{NaOH}$, $\left.56{ }^{\circ} \mathrm{C}, 1 \mathrm{~h}\right)$ lipopolysaccharide [24], or with alkalitreated $\left(0.1 \mathrm{M} \mathrm{NaOH}, 56{ }^{\circ} \mathrm{C}, 1 \mathrm{~h}\right)$ (murein)lipoprotein [21]. For sensitisation with enterobacterial common antigen, supernatant of heated $\left(1 \mathrm{~h}, 100^{\circ} \mathrm{C}\right)$ bacterial cultures or $50 \mu \mathrm{g}$ of purified antigen were added to $5 \mathrm{ml}$ of the erythrocyte suspension.

\section{Agar Gel Precipitations}

Agar gel precipitations were carried out according to Ouchterlony [25] and immunoelectrophoresis by the microtechnique of Scheidegger et al. [26] using an electrophoresis chamber from Gelman Instrument Company (model 51170-1) at a field strength of $10 \mathrm{~V} /$ $\mathrm{cm}$ for $45 \mathrm{~min}$ or for $1 \mathrm{~h}$. A sodium barbiturate buffer of $\mathrm{pH} 8.6$ was used.

\section{RESULTS}

Serological Activity of Isolated Enterobacterial Common Antigen

The material extracted from $S$. montevideo $\mathrm{SH} 94$ by a combination of phenol/water and phenol/chloroform/petroleum ether procedures and purified by DEAE-cellulose chromatography was investigated relative to its serological and immunological properties.

Amounts of $1-10 \mu \mathrm{g}$ of isolated enterobacterial common antigen were found to be sufficient for effectively coating $25 \mu \mathrm{l}$ of packed erythrocytes for the
Table 2. Serological activity of enterobacterial common antigen and lipopolysaccharide derived from $\mathrm{S}$. montevideo $\mathrm{SH}_{94}$ in the passive hemagglutination and the hemagglutination inhibition test

The material was isolated by a combined extraction method as described in detail in the preceding paper. Alkali treatment was performed with $0.25 \mathrm{M} \mathrm{NaOH}$ at $56^{\circ} \mathrm{C}$ for $1 \mathrm{~h}$; the esterification of the material was achieved with diazomethane in ether. ECAantiserum $=$ antiserum directed against $S h$. boydii $3^{-}$(F 3140); $\mathrm{O}$-antiserum $=$ antiserum directed against $S$. montevideo $\mathrm{SH} 94$; ECA-antiserum 1:640 and ECA-containing lipopolysaccharide derived from $E$. coli $\mathrm{K} 12 \mathrm{D} 21 \mathrm{e} 8$ were used for the inhibition test and the latter also as indicator antigen for the passive hemagglutination; n.d. = not detectable

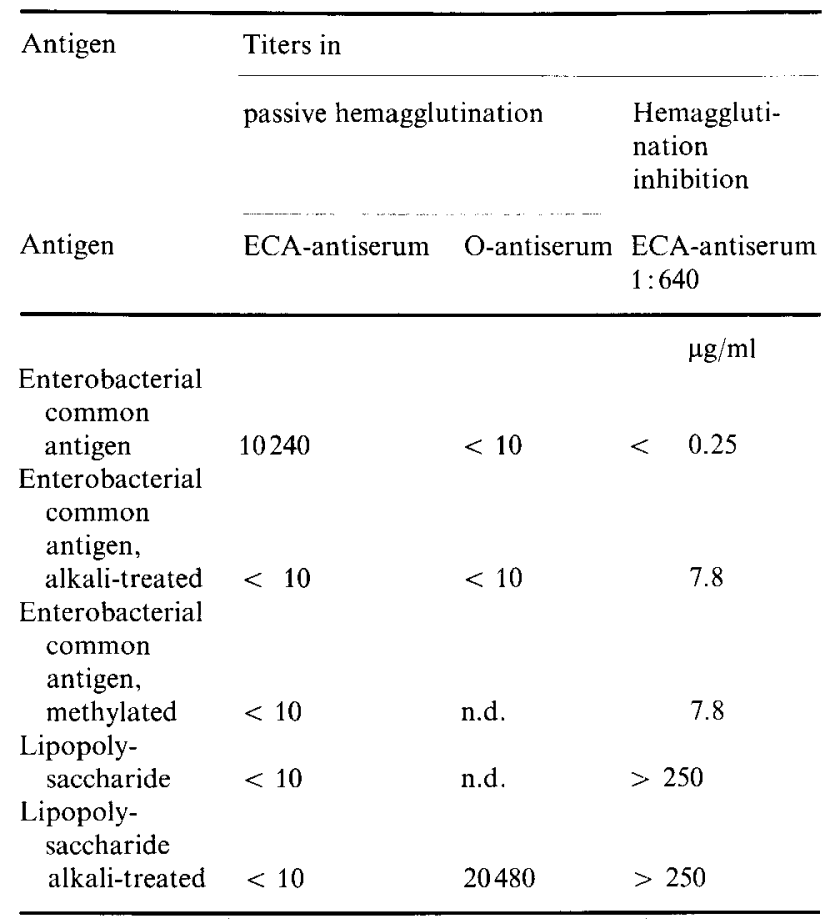

passive hemagglutination test. All antisera containing antibodies to enterobacterial common antigen showed high titers against the coated erythrocytes and, as expected, no titers were measured with antisera prepared against heat-killed non-immunogenic enterobacterial strains. Alkali treatment of isolated enterobacterial common antigen completely abolished its erythrocyte-coating capacity, a finding in accord with previous studies on alkali-treated supernatants of heated bacterial cultures [27].

The isolated material also strongly inhibited hemagglutinating systems for enterobacterial common antigen. Amounts of $0.25 \mu \mathrm{g}$ were sufficient for complete inhibition (Table 2). Although the alkali-treated material had lost the coating ability it was nevertheless a fairly good inhibitor, as was the material obtained after esterification of the carboxylic groups of the mannosaminuronic acid residues by diazomethane (Table 2). No inhibition is given by enterobacterial common antigen in the homologous $S$. montevideo SH94 O-hemagglutinating system, indicating a com- 
a)

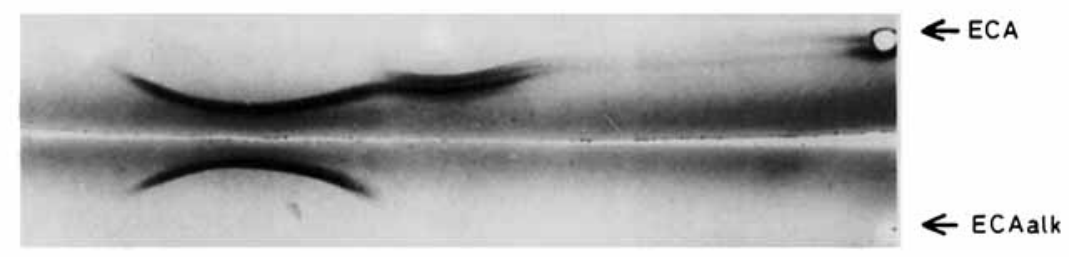

b)

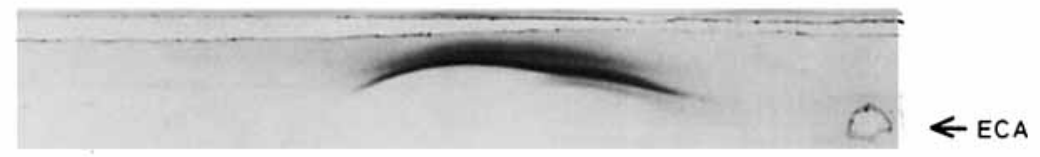

Fig.1. Immunoelectrophoresis in agar gel of enterobacterial common antigen obtained from S. montevideo SH94 before (ECA) and after treatment with alkali ( $E C$ Aalk). Two different antisera were used, both prepared with living $E$. coli 014 cells. Electrophoresis was for $1 \mathrm{~h}$ (a) or $45 \mathrm{~min}$ (b) at $10 \mathrm{~V} / \mathrm{cm}$. The agar gels were stained with Coomassie brilliant blue

plete removal of $\mathrm{O}$-antigen. This is also suggested by a lack of even trace amounts of typical lipopolysaccharide constituents, like 3-deoxy-D-manno-octulosonic acid, L-glycero-D-manno-heptose and $\beta$-hydroxy fatty acids in the purified sample (see preceding paper). In addition, no hemagglutination titers could be observed when isolated enterobacterial common antigen was tested against antisera with high titers against the isolated (murein)lipoprotein.

The characteristic precipitation pattern of isolated enterobacterial common antigen in the immunoelectrophoresis is shown in Fig. 1 a as compared to the different pattern after alkali treatment. The precipitin lines are similar to those described previously for some acidic $\mathrm{K}$ antigens of E. coli [28]. The alkali treatment resulted in a sharp precipitin line indicating that alkali is not solely splitting off some ester-linked fatty acid residues but probably cleaves intermolecular esterlinkages which may cross-link polymer chains [29]. The molecular weight of 2700 was determined with the material from the supernatant by ultracentrifugation $(4 \mathrm{~h}$ at $105000 \times \mathrm{g})$. An investigation of the corresponding pellet material showed that only the low-migrating branch of the precipitin line was visible, indicating a highly cross-linked material. A comparative chemical analysis of supernatant and pellet fractions revealed no significant differences, nor did the fractions differ in their serological activity (hemagglutination or its inhibition). With some very high-titered antisera, especially with those obtained by immunizing rabbits with living cultures of strains immunogenic for enterobacterial common antigen [18] (and M.Johns, private communication) an additional precipitin line was observable which did not fuse with the other one. The precipitin pattern is illustrated in Fig. $1 \mathrm{~b}$ and shows the additional line located towards the anode and close to the antiserum trough. This line is probably identical to the second line observed earlier by Conley et al. [11] in immunoelectrophoretic studies of ethanol extracts of a number of heated bacterial cultures.

Absorptions with several ECA-positive enterobacterial wild-type and mutant strains always eliminated all precipitating antibodies; absorptions with ECA-negative strains ( $r \mathrm{fe}^{-}$mutants as well as $r f f^{-}$ mutants) of $S$. minnesota and E. coli $08: \mathrm{K} 27^{-}$and the $r f e^{-}$mutant of E. coli 014:K7 (F1327) (see Table 1) all failed to remove precipitins to both antigens, and gave an unchanged precipitin pattern. In addition, serum absorptions with heat-killed cells of Proteus rettgeri and with erythrocytes coated with material from the supernatant of heated cultures of this strain, also eliminated all precipitating antibodies from antisera to enterobacterial common antigen (Table 3). The supernatant of a heated Proteus rettgeri culture was used by Johns et al. [18] as source of their serologically uniform common antigen. Results of the inhibition of an hemagglutinating system by enterobacterial common antigen isolated from $S$. montevideo and by heated cultures of $S$. montevideo SH94 and of Proteus rettgeri are summarized in Table 4. This indicates that material from Proteus rettgeri is also active in inhibiting a hemagglutinating system for enterobacterial common antigen although to a lesser extent.

\section{Mannosaminuronic Acid as an Essential Part of the Serological Determinant of Enterobacterial Common Antigen}

Modification of the carboxylic group of the mannosaminuronic acid residues of isolated enterobacterial common antigen by esterification with diazomethane almost completely abolished its precipitating abilities. Saponification restores the precipitating capacity, indicating that mannosaminuronic acid is an essential part of the serological determinant. As discussed above, the inhibiting capacity of the esterified material 
Table 3. Agar gel precipitation of enterobacterial common antigen obtained from S. montevideo SH94 and Proteus rettgeri by E. coli 014 antiserum after absorption with different bacterial cells and formalin-preserved erythrocytes [22] coated with bacterial supernatants The supernatants were obtained from heated $\left(100{ }^{\circ} \mathrm{C}, 1 \mathrm{~h}\right)$ bacterial cultures. E. coli 014 antiserum was absorbed with different cells or substances as listed in the table and then used for agar gel precipitation

\begin{tabular}{lll}
\hline $\begin{array}{l}\text { E. coli } 014 \text { antiserum } \\
\text { absorbed with }\end{array}$ & \multicolumn{2}{l}{ Precipitation of } \\
\cline { 2 - 3 } & $\begin{array}{l}\text { enterobacterial } \\
\text { common antigen }\end{array}$ & $\begin{array}{l}\text { Proteus rettgeri } \\
\text { supernatant }\end{array}$ \\
\hline Unabsorbed & + & + \\
E. coli 014 cells & - & - \\
S. montevideo SH94 cells & - & - \\
Proteus rettgeri cells & - & - \\
E coli 014 rfe- cells & + & + \\
Erythrocytes & + & + \\
Erythrocytes coated with & & \\
$\quad \begin{array}{l}\text { S. montevideo SH94 } \\
\text { supernatant }\end{array}$ & - & - \\
Erythrocytes coated with & & - \\
$\quad \begin{array}{l}\text { Proteus rettgeri } \\
\text { supernatant }\end{array}$ & & \\
\hline
\end{tabular}

is also weaker than that of the free enterobacterial common antigen.

Attempts to find serological cross-reactions in the passive hemagglutination test and in Ouchterlony gel precipitation with other mannosaminuronic-acidcontaining antigens (K7 and $\mathrm{K} 56$ antigen of $E$. coli, glucose-mannosaminuronic-acid polymer from $M$. lysodeikticus cell wall) were unsuccessful. The hemagglutination titer was not changed when the antiserum was incubated with these antigens prior to the hemagglutination test, nor did a serum absorption with $M$. lysodeikticus cells remove enterobacterial common antigen antibodies. Whether mannosaminuronic acid in these antigens is also an essential part of the immunodeterminant has not been established.

\section{Immunogenicity \\ of Isolated Enterobacterial Common Antigen}

Attempts to induce antibodies to enterobacterial common antigen in the rabbit by intravenous immunization with the isolated antigen were unsuccessful, even when comparably high amounts (up to $400 \mu \mathrm{g}$ / injection) of supernatant (PL-L) or pellet material (PL-S) after separation of the phenol-soluble PL fraction by ultracentrifugation) were used for the immunization. Contrary to these results, intravenous immunization of rabbits with the same material adsorbed onto acetic acid-treated S. minnesota R595 bacteria afforded high titers specific for enterobacterial common antigen (Table 5). S. minnesota R595 is an $\mathrm{R}$ mutant of chemotype Re which carries in addition an $r f e$ defect, which makes this mutant also ECA-
Table 4. Comparison of the inhibitory capacity of lipopolysaccharide and enterobacterial common antigen obtained from $\mathrm{S}$. montevideo SH94 and Proteus rettgeri

Lipopolysaccharide and enterobacterial common antigen were isolated by the combined extraction procedure described in the preceding paper. $P$. rettger $i$ water phase was material obtained after phenol/water extraction according to Westphal [30]. The supernatants were obtained from heated $\left(100^{\circ} \mathrm{C}\right)$ bacterial cultures. The antiserum used was prepared by immunization of rabbits with heatkilled $S h$. boydii type $3^{-}$cells and diluted 1:640. The erythrocytes were sensitized with enterobacterial-common-antigen-containing lipopolysaccharide from E. coli K12 D21e8 (- no inhibition, $+/++$ degrees of inhibition)

\begin{tabular}{ll}
\hline Material & $\begin{array}{l}\text { Hemagglutination } \\
\text { inhibition }\end{array}$ \\
\hline Lipopolysaccharide & - \\
Enterobacterial common antigen & ++ \\
$P$. rettgeri water phase & + \\
P. rettgeri supernatant & + \\
S. montevideo SH 94 supernatant & ++ \\
\hline
\end{tabular}

Table 5. Hemagglutination titers of the antiserum prepared with cells of acetic-acid-hydrolyzed S. minnesota $R 595$ coated with enterobacterial common antigen from $\mathrm{S}$. montevideo SH94 before and after absorption with $\mathrm{S}$. typhimurium his 642 ECA-positive Ra mutant and $\mathrm{S}$. typhimurium his386 ECA-negative Ra mutant cells

The erythrocytes were sensitized with enterobacterial-commonantigen-containing lipopolysaccharide from $E$. coli K12 D21e8

\begin{tabular}{ll}
\hline Antiserum absorbed with & $\begin{array}{l}\text { Titer in passive } \\
\text { hemagglutination }\end{array}$ \\
\hline Unabsorbed & 2560 \\
ECA-negative his386 & 2560 \\
ECA-positive his 642 & $<10$ \\
\hline
\end{tabular}

negative [15]. Immunization with acetic-acid-treated R595 bacteria was first introduced by Galanos et al. [20] for obtaining lipid A antibodies in the rabbit. The rise of enterobacterial common antigen titers in two representative rabbits is shown in Fig. 2. The titer persists for a longer period of time. No antibodies to enterobacterial common antigen were found in control animals which were immunized under identical conditions with uncoated acetic-acid-treated R595 bacteria. The specificity of the antibody response was documented by specific absorptions using two closely related $S$. typhimurium Ra mutants which were ECAnegative (strain his386) or ECA-positive (strain his642). Titers for antibodies to enterobacterial common antigen could be completely removed by absorption with a culture of the ECA-positive strain, but remained unchanged when the ECA-negative mutant was used for the absorption (Table 5). As expected, all antisera contained in addition high lipid A titers, which could be measured by the passive hemolysis test [20]. 


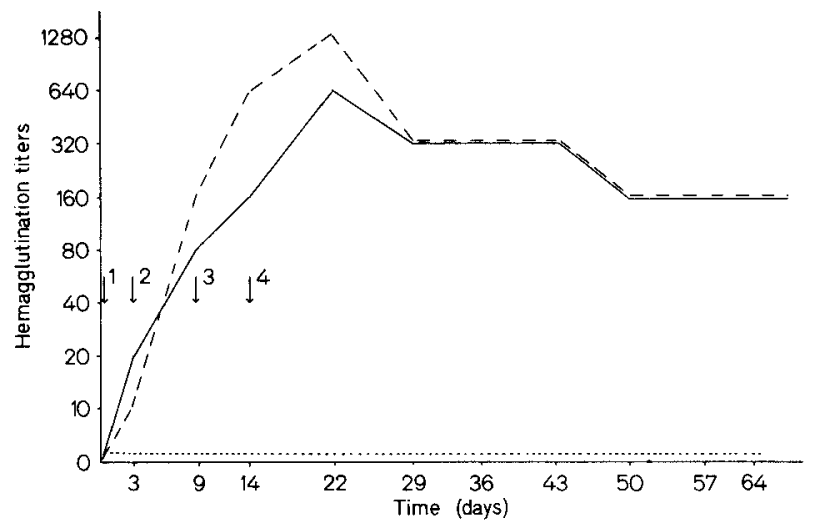

Fig. 2. Time course of antibody titers specific for enterobacterial common antigen in the passive hemagglutination test in two rabbits after immunization with acid-hydrolyzed cells of S. minnesota $R 595$ $[20]$ coated with enterobacterial common antigen isolated from $\mathrm{S}$. montevideo $S H 94$. Immunization with $10^{9}$ coated bacterial cells on day $0,3,9$, and 14 as indicated by arrows. (-) Each immunization with acid-hydrolyzed S. minnesota R595 cells incubated with $100 \mu \mathrm{g}$ enterobacterial common antigen; (----) S. minnesota R595 cells for the first three immunizations incubated with $10 \mu \mathrm{g}$ enterobacterial common antigen, for the fourth immunization incubated with $100 \mu \mathrm{g} ;(\cdots)$ ) control animals immunized with uncoated acid-hydrolyzed $S$. minnesota R595 cells

For investigation of the immunogenicity of isolated enterobacterial common antigen in mice, groups of five mice (NMRI, female, 6-8-weeks old) were immunized directly with the isolated antigen or with $S$. minnesota R595 bacteria coated with the antigen. For the immunization with the isolated antigen, amounts of $0.01-10 \mu \mathrm{g}$ of the isolated antigen in saline were administered intravenously. Antigen-coated, acetic-acid-treated bacteria ( $10 \mu \mathrm{g}$ enterobacterial common antigen/1 mg R595 bacteria) were used for intravenous, intraperitoneal and subcutaneous immunization. Additional groups of mice were immunized with heat-killed suspensions of the ECA-immunogenic strain E. coli 014:K7 (F2387) or, for control purposes, with uncoated R595 bacteria or saline alone. The antibody response under the various conditions is shown in Fig. 3. The intravenous administration of $1-10 \mu \mathrm{g}$ of free enterobacterial common antigen in saline gave a transient formation of antibodies with the highest titer on day 7 after the first injection (the titers being 32 with $1 \mu \mathrm{g}$ and 128 with $10 \mu \mathrm{g}$ ). The titers fell off rapidly and were not increased by a booster injection on day 35 with the same antigen. In contrast the antibody response after intravenous and intraperitoneal immunization with coated acetic-acid-treated R595 bacteria was similar to that obtained with a heat-killed suspension of E. coli 014:K7 bacteria. Maximum titers were observed 5 days after the last injection of the antigen, i.e. on day 21 . The titers found after intraperitoneal immunization were generally higher than those observed after intravenous immuni-

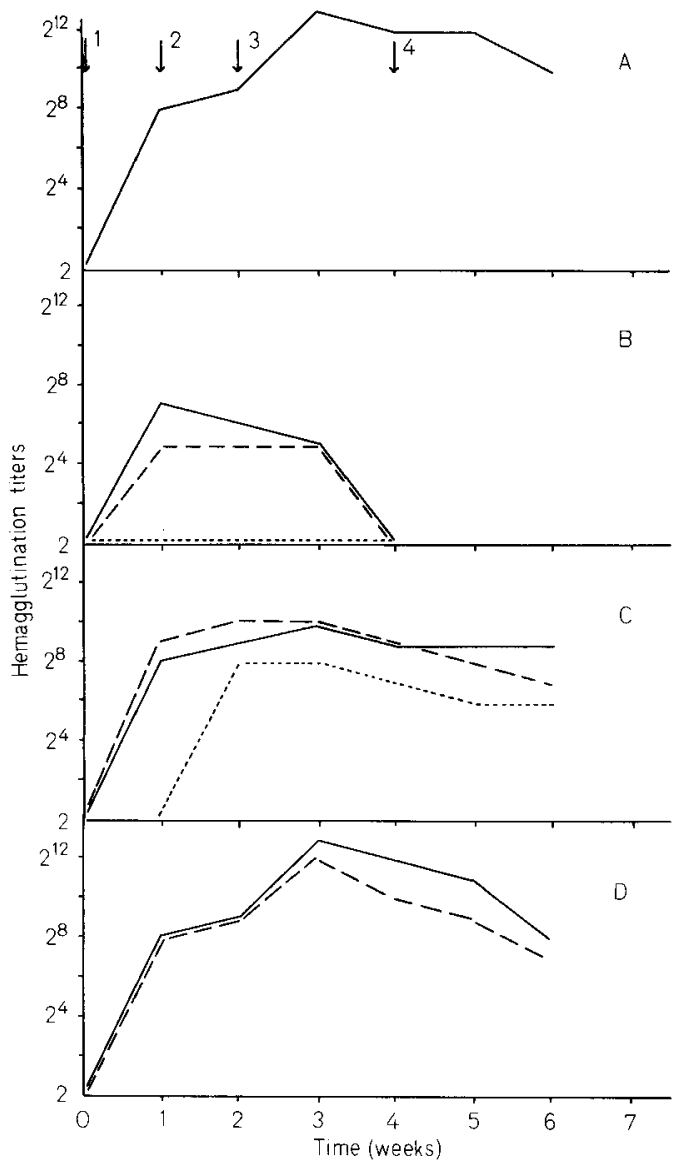

Fig. 3. Time course of antibody titers specific for enterobacterial common antigen in the passive hemagglutination test in mice after immunization with different antigen preparations. Each titer represents the average titer determined in sera from five mice (NMRI, female). Immunizations of the animals were done on day 1 , 8,16 , and 30 as indicated by arrows. Time course of ECA-specific titers after immunization with: (A) $10^{8}$ heat-killed E. coli 014 cells intravenously; (B) isolated enterobacterial common antigen from S. montevideo, $(\cdots) 10 \mathrm{ng}$ and $100 \mathrm{ng},(---) 1 \mu \mathrm{g},(-)$ $10 \mu \mathrm{g}$; (C) acid-hydrolyzed $S$. minnesota R595 cells [20] coated with enterobacterial common antigen from $S$. montevideo SH94, ( . . . .) $1 \mu \mathrm{g}$ on $10^{7}$ cells, $(---) 10 \mu \mathrm{g}$ on $10^{7}$ cells, $(\longrightarrow) 100 \mu \mathrm{g}$ on $10^{8}$ cells intravenously; (D) acid-hydrolyzed S. minnesota R595 cells coated with enterobacterial common antigen from $S$. montevideo SH94, (_- ) $10 \mu \mathrm{g}$ on $10^{7}$ cells, $100 \mu \mathrm{g}$ on $10^{8}$ cells intraperitoneally

zation. When a booster injection was given 2 weeks after the last immunization, the titers persisted for a long time (Fig. 3). No titers were found after subcutaneous immunization of the animals, or after administration of uncoated R595 bacteria or saline alone.

The specificity of the immune response was again ascertained by absorption experiments; $\mathrm{R}$ mutants of E. coli $08:{\mathrm{K} 27^{-}}^{-}$which were either ECA-positive (F470 and $\mathrm{F} 614)$ or ECA-negative $\left(\mathrm{F} 1283=r f e^{-}\right.$ mutant; or $\mathrm{F} 1373=r f f^{-}$mutant) and also from $E$. coli 014:K7 (F2387 being ECA-positive and F1327 
being ECA-negative) (see Table 1) were used for the absorptions. The ECA-negative $r f e^{-}$and $r f f^{-}$mutants were not able to remove the antibodies in contrast to the ECA-positive strains, which removed the titers completely.

\section{DISCUSSION}

Enterobacterial common antigen, isolated from $S$. montevideo SH94 by the combined phenol/water and phenol/chloroform/petroleum ether extraction procedure and purified by DEAE-cellulose chromatography, was found to be free of residual lipopolysaccharide and lipoprotein. This was demonstrated by the lack of reactivity of the isolated high-titred O-antiserum and lipoprotein antiserum in the passive hemagglutination test and by the absence of characteristic lipopolysaccharide constituents, like 3-deoxy-D-mannooctulosonic acid, heptose or $\beta$-hydroxy fatty acids.

Isolated enterobacterial common antigen gave all the serological reactions described so far for this antigen including coating of erythrocytes, reactivity with antisera to enterobacterial common antigen, high activity in hemagglutination tests and inhibition and gel precipitation with high-titred antisera to enterobacterial common antigen $[12,18]$. The erythrocyte-coating capacity is probably due to the amphipathic character of the antigen. Removal of fatty acid by alkali treatment abolishes the coating capacity [12]. Lipid-free polysaccharides usually do not coat erythrocytes but can acquire this property when acylated even to a very low extent [31]. The removal of palmitic acid by alkali treatment does not destroy the inhibiting capacity, although it is lowered (Table 2). From the precipitin pattern before and after alkali treatment it is obvious that the material is more homogeneous after the alkali treatment. Modification of its mannosaminuronic acid residues by esterifying the carboxylic groups alters the precipitating property drastically (a reaction which can be reversed). It is therefore very likely that mannosaminuronic acid residues are essential parts of the serologic determinant. No serologic cross-reactions could, however, be observed with other mannosaminuronic-acid-containing antigens.

The question of whether enterobacterial common antigen is a uniform antigen or a mixture of two distinct antigenic entities is raised by the results of the agargel precipitation. Two separate, non-confluent precipitin lines were sometimes observed with very hightitered antisera to enterobacterial common antigen. This was recognized earlier by $\mathrm{McCabe}$ and Johns (personal communication discussed in [3]) with our most purified material (fraction PL-L-DEAE). It should be noted, however, that absorptions of these precipitating antisera with ECA-negative mutants (genetically $r f e^{-}$as well as $r f f^{-}$mutants) did not lead to a change of the precipitin pattern, indicating that all the precipitating material is absent in ECA-negative mutants of both types. Absorptions of the precipitating antisera with the genetically related ECApositive strains always led to a simultaneous removal of all precipitins regardless of whether absorptions were carried out with heat-killed or living bacteria. Further studies are needed to explain why enterobacterial common antigen exists in two serologically distinct antigenic forms and to reveal the structural basis for this.

The immunogenicity of crude isolated enterobacterial common antigen in the rabbit is dependent on its degree of aggregation. This was clearly established by Whang et al. [9] using millipore filtration for separating aggregated (immunogenic) and non-aggregated (non-immunogenic) material. Studies by Neter et al. [32] with cell-attached crude material, coated either to homologous or heterologous erythrocytes or to C3H mouse fibroblast ( $\mathrm{L}$ ) cells, showed that antibodies are only provoked in the rabbit with the cell-bound but not with the soluble material. Addition of highly purified lipopolysaccharide to the aggregated form reduced its immunogenicity to a considerable extent [8], a phenomenon which is not completely understood and not solely explained as a result of disaggregation caused by lipopolysaccharide [3]. The immunological tolerance to polysaccharide antigens of low molecular weight is a well-documented phenomenon $[33,34]$ and could also be responsible for the observed change in immunogenicity.

The immunological properties of the isolated and purified enterobacterial common antigen from $S$. montevideo SH94 fits the data obtained so far with crude isolates of the soluble form. A good antibody response in rabbits and NMRI mice is obtained when the isolated material is attached to acetic-acid-treated S. minnesota $\mathrm{R} 595$ bacteria and when the animals are immunized intravenously (rabbits and mice) or intraperitoneally (mice) with this complex. This method, introduced by Galanos et al. [20], was also successfully applied for preparation of antisera against the isolated Vi antigen of S. typhi (Falk, unpublished results). Acetic-acid-treated R595 bacteria have lipid A and lipoprotein exposed in their outer membrane. Both of these substances are known for their high mitogenic activity $[35,36]$.

The antibody production in mice was not stimulated by subcutaneous immunization under the conditions applied. The titers in passive hemagglutination observed after intraperitoneal immunization of mice were, however, approximately the same as those obtained by immunizing NMRI mice with a suspension of the highly immunogenic E. coli 014:K7 strain. Much lower titers were observed by Gorzynski et al. [37] when four different mouse strains (three inbred, one outbred) were immunized with soluble crude 
enterobacterial common antigen administered intraperitoneally with or without incomplete Freund's adjuvant. Whether the difference in immunogenicity is due to the immunization route or to strain-specific variations as described previously [37] has yet to be investigated. When enterobacterial common antigen was directly used as immunogen $(1-10 \mu \mathrm{g}$ in saline) an immediate antibody response was observed, but the titers rapidly fell off, and the mice then became unresponsive to a booster injection with the same antigen. This finding is similar to observations by Gorzynski et al. [37], when CBA and C57BL mice were intraperitoneally immunized with isolated crude enterobacterial common antigen.

Whether or not animals are protected against enterobacterial infections by antibodies to enterobacterial common antigen is not yet unequivocally answered [38-40] and needs further studies. The data obtained with the purified material show that the isolated antigen has retained the serological and immunological characteristics of the Kunin antigen. Previous studies on isolated and purified materials with serological common antigen specificity were carried out with materials which were not, or not sufficiently, chemically characterized and often the isolate had lost some characteristic properties of enterobacterial common antigen, e.g. erythrocyte-coating capacity [18] or immunogenicity $[2,18]$. The immunogenic material isolated by Marx and Petcovici [41], however, was shown in our hands to contain considerable amounts of the GlcN/ManNUA polymer, although in combination with other (cephalin-like) lipid material.

The question as to whether materials isolated as common antigen of the Kunin type by other groups represent different antigens has to be studied in detail. The characterization of D-mannosaminuronic acid as an essential part of the sugar moiety of enterobacterial common antigen can be used in future studies to find out whether materials isolated as common antigens are structurally related to the material described here. The presence of the GlcN/ManNUA polymer in all enterobacterial strains investigated so far [3] and characterized by serological means as ECA-positive strains is the strongest support for the identity of our isolated material with the Kunin antigen, as is the lack of the polymer (or its presence in only trace amounts) in all mutant strains which were characterized by serological means as ECA-negative. These studies will be described elsewhere.

We thank Miss Ch. Widemann for expert technical assistance, and Drs S. Bhakdi and W. Falk for experimental help. We are greatly indebted to Drs P. H. Mäkelä, Helsinki, and G. Schmidt for providing ECA-negative mutants, and to Drs M. A. Johns and W. $\mathrm{R}$. McCabe for the Proteus rettgeri strain and valuable discussions.

\section{REFERENCES}

1. Kunin, C. M., Beard, M. V. \& Halmagyi, N. E. (1962) Proc. Soc. Exp. Biol. Med. 111, 160-166.

2. Kunin, C. M. (1963) J. Exp. Med. 118, 565-586.

3. Mäkelä, P. H. \& Mayer, H. (1976) Bacteriol. Rev. 40, $591-$ 632.

4. Kunin, C. M. \& Beard, M. V. (1963) J. Bacteriol. 85, 541548.

5. Gorzynski, E. A. \& Neter, E. (1970) Infect. Immun. 2, 767- 771.

6. Schmidt, G., Jann, B. \& Jann, K. (1974) Eur. J. Biochem. 42, 303-309.

7. Whang, H. Y., Mayer, H., Schmidt, G. \& Neter, E. (1972) Infect. Immun. 6, 533-539.

8. Whang, H. Y. \& Neter, E. (1967) Proc. Soc. Exp. Biol. Med. 124, 919-924.

9. Whang, H. Y., Chun, D., Yagi, Y. \& Neter, E. (1970) Int. Arch. Allergy, 38, 57-67.

10. Gorzynski, E. A., Whang, H. Y., Suzuki, T. \& Neter, E. (1963) Proc. Soc. Exp. Biol. Med. 114, 700-704.

11. Conley, F. E., Johns, M. A. \& McCabe, W. R. (1976) Abstr. Annu. Meet. Am. Soc. Microbiol., B 25.

12. Mayer, H. \& Schmidt, G. (1971) Zentralbl. Bakteriol. Parasitenkd. Infektionskr. Hyg. Abt. I Orig. Reihe A 216, 299-313.

13. Schmidt, G., Mayer, H. \& Mäkelä, P. H. (1976) J. Bacteriol. $127,755-762$.

14. Eriksson-Grennberg, K. G., Nordström, K. \& Englund, P. (1971) J. Bacteriol. 108, 1210-1223.

15. Mäkelä, P. H., Mayer, H., Whang, H. Y. \& Neter, E. (1974) J. Bacteriol. 119, 760-764.

16. Nikaido, H., Levinthal, M., Nikaido, K. \& Nakane, K. (1967) Proc. Natl Acad. Sci. U.S.A. 57, 1825-1832.

17. Mäkelä, P. H., Schmidt, G., Mayer, H., Nikaido, H., Whang, H. Y. \& Neter, E. (1976) J. Bacteriol. 127, 1141-1149.

18. Johns, M. A., Whiteside, R. E., Baker, E. E. \& McCabe, W. R. (1973) J. Immunol. 110, 781-790.

19. Schlecht, S. (1975) Zentralbl. Bakteriol. Parasitenkd. Infektionskr. Hyg. Abt. I Orig. Reihe A 232, 61-72.

20. Galanos, C., Lüderitz, O. \& Westphal, O. (1971) Eur. J. Biochem. 24, 116-122.

21. Braun, V., Bosch, V., Klumpp, E. R., Neff, I., Mayer, H. \& Schlecht, S. (1976) Eur. J. Biochem. 62, 555-566.

22. Bing, D. H., Weyand, J. G. M. \& Stavitsky, A. B. (1967) Proc. Soc. Exp. Biol. Med. 124, 1166-1170.

23. Taylor, R. L. \& Conrad, H. E. (1972) Biochemistry, 11, 13831388.

24. Neter, E. (1956) Bacteriol. Rev. 20, 166-188.

25. Ouchterlony, Ö. (1958) Prog. Allergy, 5, 1-77.

26. Scheidegger, J. J. (1955) Int. Arch. Allergy, 7, 103-110.

27. Whang, H. Y., Mayer, H. \& Neter, E. (1971) J. Immunol. 106, $1552-1558$.

28. Qrskov, F., Qrskov, I., Jann, B. \& Jann, K. (1971) Acta Pathol. Microbiol. Scand. 79, 142-152.

29. Hungerer, D., Jann, K., Jann, B., Qrskov, F. \& Qrskov, I. (1967) Eur. J. Biochem. 2, 115-126.

30. Westphal, O., Lüderitz, O. \& Bister, F. (1952) Z. Naturforsch. $7 b, 148-155$.

31. Hämmerling, U. \& Westphal, O. (1967) Eur. J. Biochem. I, $46-50$.

32. Neter, E., Whang, H. Y., Suzuki, T. \& Gorzynski, E. A. (1964) Immunology, 7, 657-664.

33. Howard, J. G. \& Mitchison, N. A. (1975) Progr. Allergy, I8, $43-96$.

34. Dresser, D. W. \& Mitchison, N. A. (1968) Adv. Immunol. 8, 129-181.

35. Melchers, F., Braun, V. \& Galanos, C. (1975) J. Exp. Med. 142, 473-482. 
36. Andersson, J., Melchers, F., Galanos, C. \& Lüderitz, O. (1973) J. Exp. Med. 137, 943-953.

37. Gorzynski, E. A., Neter, E. \& Ambrus, J. L. (1970) Proc. Soc. Exp. Biol. Med. 134, 776-779.

38. Domingue, G. J., Salhi, A., Rountree, C. \& Little, W. (1970) Infect. Immun. 2, 175-182.

D. Männel and H. Mayer, Max-Planck-Institut für Immunbiologie, Stübeweg 51, D-7800 Freiburg-Zähringen, Federal Republic of Germany
39. Gorzynski, E. A. \& Krasny, S. A. (1975) Med. Microbiol. Immunol. 16I, 163-170.

40. McCabe, W. R. \& Greely, A. (1973) Infect. Immun. 7, 386392.

41. Marx, A. \& Petcovici, M. (1975) Zentralbl. Bakteriol. Parasitenkd. Infektionskr. Hyg. Abt. I Orig. 233, 486-494. 